\title{
Application of the Methods for Comprehensive Reliability Analysis of District Heating Systems
}

\author{
Ivan POSTNIKOV ${ }^{1 *}$ \\ ${ }^{1}$ Melentiev Energy Systems Institute of Siberian Branch of the Russian Academy of \\ Science (ESI SB RAS), Irkutsk, Russia
}

\begin{abstract}
The general idea of the methodology for the comprehensive reliability analysis of district heating systems (DHS), developed earlier by the author of this paper, is a joint considering and modelling of each technological processes, including fuel supply to heat sources (HS), generation of heat energy by these HS and its distribution on district heating network (HN). For solving this problem different methods and models are applied: statistical testing method, Markov random processes, methods of the theory of hydraulic circuits, basic laws of district heating and heat transfer processes, etc. In this paper the main attention is paid to the results of the practical application of methods and models of a comprehensive reliability analysis of DHS using the example of calculations performed for the actual DHS scheme of the Shelekhov city (Irkutsk region, Russia). Different stages of the case study are considered, including preparation of initial data, simulation modelling of fuel supply to HS, modelling of the Markov random process describing operate of DHS, calculation of post-failure modes in HN, evaluation of nodal reliability indices (RI), decomposition analysis of reliability. Based on the analysis of calculation results some preliminary directions are formulated to the increase of reliability for studied DHS. These data are the basis for a comprehensive reliability synthesis (optimization) of DHS, the solution of which is the subject of special perspective stage in development of the research.
\end{abstract}

Keywords - Comprehensive reliability analysis; decomposition of reliability; district heating system; graph of states; Markov random process; nodal reliability indices; statistical testing method; system of fuel supply; theory of hydraulic circuits

\section{INTRODUCTION}

Since the creation of the first district heating systems (DHS) based on cogeneration power plants, back in the middle of 20th century, district heating is one of the most effective ways to provide heat energy to urban consumers, especially for territories with a cold climate. So, district heating in cities with a cold climate is socially and economically significant, and the reliable and safe functioning of DHS is one of the priority conditions for the stability and development of the economy for countries with a high share of district heating (Russia and other countries of Eastern Europe, some countries of Northern Europe, China).

In recent years, the problem of the reliability and efficiency of the functioning of DHS has acquired new aspects related to the technological development of these systems, in particular the transition to so-called DHS of the 4th generation (4GDH systems) [1]-[5]. This transition is consistent with the global trend when integrated energy systems with intelligent control are being formed.

* Corresponding author.

E-mail address: postnikov@isem.irk.ru 
Research on the reliability of DHS using mathematical methods of the theory of reliability and probability theory began to develop in the late 1960s - early 1970s [6]. According to the prevailing scientific and design methodology, the solution of reliability problems for DHS is carried out separately for their subsystems: heat sources (HS) and heat network (HN) [6].

The HS of different types, technologies and capacities have a number of common features as objects of reliability research. In most DHS, combined heat and power plants (CHP) are applied as HS. This allows the technological scheme of any HS to be presented in the form of separate units (components or their groups) with a specific function and parameters, combined into unified serial and parallel structural circuits for reliability study. The degree of aggregation of the initial scheme of HS is determined by purpose and the required detailing of results of the reliability calculation. Methods for reliability analysis of HS can be divided into analytical and statistical modelling methods.

Methods of the first group are mainly based on the application of models of Markov [6], [7]-[14], Semi-Markov random processes [6], [15], [16], and other logical and probabilistic algorithms [6], [17]-[19]. In this case, the solution of reliability problems is carried out on HS calculated schemes with specified reliability parameters of components. A typical methodology for reliability analysis of HS, based on the use of Markov and Semi-Markov random processes, includes the following stages: the formation the set of possible states corresponding to failures of different components; formation of the structure of events associated with failures and restorations of components of the calculation scheme (usually in the form of an oriented graph states and relations between them); solving the equations system of the Markov random process that describes the given structure of events to determine the probabilities of states; assessment of emergency modes parameters (consequences of components failures); determination of RI characterizing different properties of reliability of the studied HS.

Methods of the second group for reliability analysis of HS (statistical modelling methods) are related to imitation algorithms which usually are based on the Monte Carlo method to modelling of possible states of an object. Some of these methods are presented in [6], [20][22]. A detailed component scheme of HS is not required for these algorithms, and the initial information for modelling is statistical data on the failures of the studied object (or its analogue) over a certain time period. It should be noted that the application of this approach in practice is impossible due to the lack of the necessary array of statistical data for the formation of a representative sample.

A comprehensive approach to the reliability analysis of $\mathrm{HN}$ was first proposed in 1972 [23], in which the basic principles of calculating the reliability and redundancy of HN were formulated. As a result of the further development of this approach a technique for analysis the nodal reliability of HS was developed in Energy Systems Institute of Siberian Branch of the Russian Academy of Sciences (ESI SB RAS) [6], [24]-[26]. In this technique, the methods of the theory of hydraulic circuits (THC) [27] are used to calculate the emergency modes in $\mathrm{HN}$ corresponding to failures of its components (sections or branches), and probabilities of network states related to these failures are determined using simplified models of Markov random process. The final assessment providing by nodal reliability indices (RI) is a quantitative level of reliability properties of the system.

Along with the nodal approach assessing the reliability of $\mathrm{HN}$, there is another concept based on the use of integrated RI [6], [28], [29]. The integrated RI determines the quantitative level of required functions performance or some reliability property averaged for $\mathrm{HN}$ as a whole during the calculation period. This approach does not require multivariate calculations of emergency modes in HN and it is well suited for express reliability analysis. At the same time, only a nodal reliability analysis allows us to ensure RI decomposition with the 
identification of "bottlenecks" and the most severe failures leading to a long-term interruption of heating to consumers.

The reliability of heat supply to consumers along with the availability and failure-free operation of DHS operation is also determined by the uninterrupted fuel supply to HS. In this regard, the assessment of the reliability of fuel supply to HS is an integral stage in a systematic (comprehensive) approach to solving the problems of analysis and synthesis of the reliability of heating to consumers. The complex of objects for production, transportation and storage of fuel for HS is a system of fuel supply (SFS). These systems are different in type of fuel (coal, oil, gas, etc.), structure and scale. The one of approaches to the reliability analysis of SFS (fossil fuel supply to CHP) based on the method of statistical testing (Monte Carlo method) is presented in [30]. In this methodology, to determine possible coal shortages for HS caused by malfunctions of SFS functioning, the probability distributions of random variables of fuel needs and fuel supply for a certain period of time are used. Some other issues connected with impacting different factors (internal and external) on the irregularity and reliability of the fuel supplying and consumption on HS are considered in [31], [32].

Along with methods of statistical modelling, techniques for the reliability analysis of pipeline SFS (oil and gas supply) are widely applied based on combining deterministic network models of operating modes (mainly hydraulic, with use of unified models of THC) and models of Markov random processes for the probabilistic description of system states [33]. As practice shows, this approach is most effective for solving the problems of reliability for pipeline energy systems. Many aspects of reliability problems of pipeline SFS are common with similar ones for other energy pipeline and network systems (oil, gas, electricity etc.) $[34]-[37]$.

As follows from the review, the existing methods for solving the reliability (analysis and synthesis) problems of SFS, HS and HN are aimed at separate analysis and modelling of these systems, which does not allow considering joint failures of components of these systems and their impact on the level of emergency heating to consumers. As a result, the separation solving of these problems leads to results that do not allow determining the actual level of reliability of heating to consumers.

An analysis of the considered existing methodical approaches made it possible to formulate directions for their development and improvement, substantiate the scientific and practical significance of a comprehensive (jointed) studying of the reliability of SFS, HS and HN, formulate problems of a comprehensive reliability analysis of DHS and its conceptual methodological principles. To solve these problems, a methodology for the comprehensive reliability analysis of DHS is previously developed by the authors of this article, in which the disadvantages of separate reliability assessing of studied systems (SFS, HS and HN) are eliminated. This methodology is presented in detail in several of the following publications [25], [26], [38]-[40], and here it is not considered. In the framework of proposed approaches the methodological compatibility is ensured for various calculating results of reliability of these systems to determine the total (summary) impact of all stages of production and distribution of thermal energy on the reliability of heating to consumers. This article presents the results and a brief description of stages of practical (case) studies conducted applying the developed methods for a comprehensive reliability analysis of DHS of Shelekhov city, Irkutsk region (Russia). 


\section{COMPREHENSIVE ANALYSIS OF THE DHS OF SHELEKHOV CITY, IRKUTSK REGION (RUSSIA)}

According to the methodology presented in [25], [38]-[40], a comprehensive reliability analysis of DHS taking into account fuel supply to HS was carried out in 5 following stages.

1. Preparation of initial data, calculation schemes.

2. Reliability analysis of SFS (fuel supply to HS).

3. Modelling of a Markov random process describing the operation of DHS.

4. Modelling of emergency modes of DHS.

5. Determining of nodal RI.

The calculations were carried out using Maple, GAMS and MS Excel software.

In the section 3 the results of a decomposition reliability analysis is presented, which allows us to identify the impact of each of the studied subsystems on the reliability of heat supply to consumers.

\subsection{Preparation of Initial Data, Calculation Schemes}

As part of the DHS of Shelekhov city, Irkutsk region, there is one centralized HS and HN with looped circuit structures. The source is CHP-5 of energy company "Irkutskenergo" with installed heat capacity of $512 \mathrm{MW}$ (with peak electric boiler). The length of transmission pipelines of $\mathrm{HN}$ is $15.7 \mathrm{~km}$. The formation of the initial data for the reliability analysis for the DHS of Shelekhov is based on the report [41]. Fig. 1(a) shows a DHS scheme of Shelekhov on the city map. The district heat supply areas of the city are conditionally divided into "western" and "eastern". The "western" area includes the $1^{\text {st }}, 3^{\text {rd }}, 4^{\text {th }}$, and Central districts. The "eastern" area includes the Railway station district, from the 1 st to the 11 th, 18th, 20th and 30th quarters, as well as a park zone. The heat load connected to CHP-5, taking into account losses and constant consumption of hot water, is $193 \mathrm{MW}$, of which $59 \%$ related to the "eastern" area and $41 \%$ to the "western" one. The total actual load of consumers is about $170 \mathrm{MW}(1830 \mathrm{t} / \mathrm{h})$.
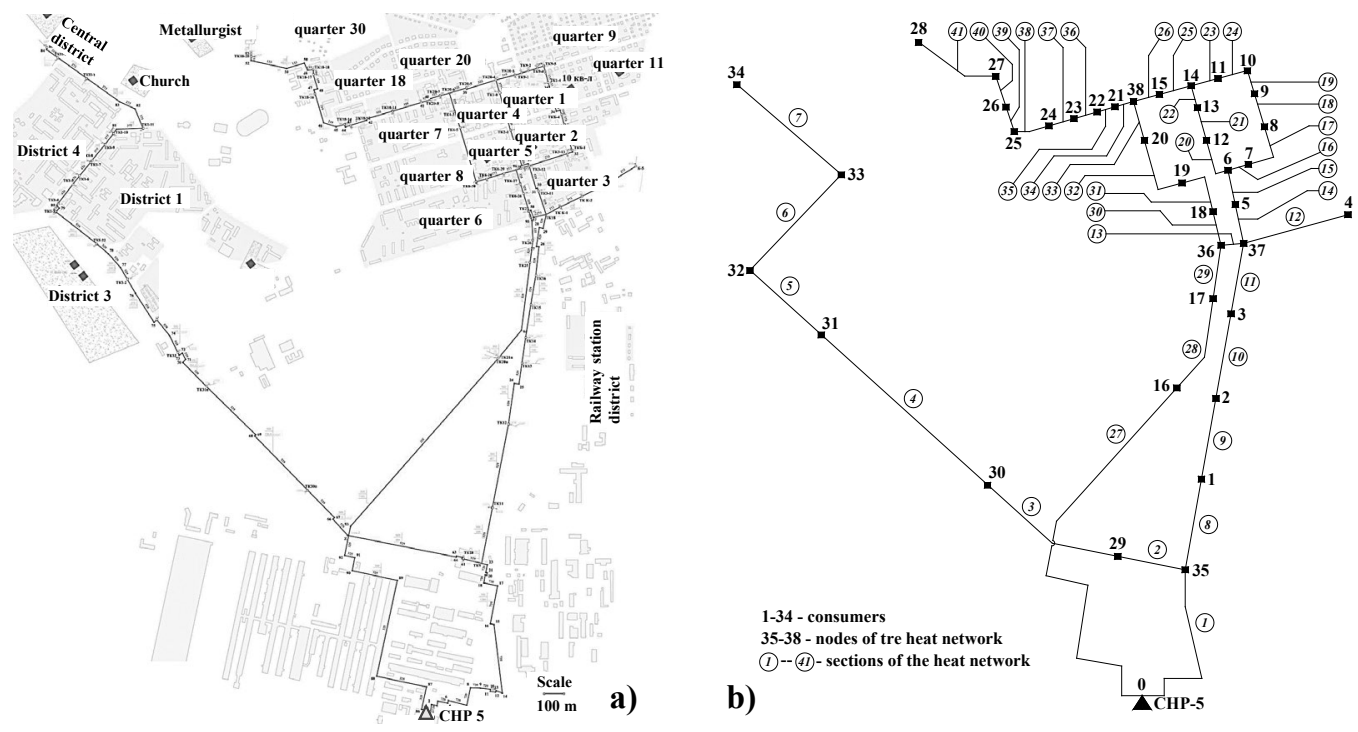

Fig. 1. Schemes of DHS in Shelekhov: a) general scheme on the city map; b) aggregated calculated scheme. 
The aggregated scheme of DHS in Shelekhov is presented in Fig. 1b, which was obtained by combining several consumers into one united. This scheme consists of 41 section of the network and 34 united consumers (further as consumers), the loads of which are presented in Fig. 2. The load of each consumer includes two part: heating and hot water supply. Main technical parameters of components (branches, sections) of HN (diameters and lengths) and their reliability parameters (failure and restoration rates) are given in the Table 1. Reliability parameters of the HN components are considered for two conditions: without and with the emergency and restoration service (ERS) [6].

The main equipment of the CHP-5 consists of seven steam boilers BKZ-75-39FB with a total capacity of $525 \mathrm{t} / \mathrm{h}(406 \mathrm{MW})$ and 3 steam turbines with backpressure R-6-35/5 with a capacity of $6 \mathrm{MW}$ each [41]. Steam pipelines in the plant have diameters from 159 to $273 \mathrm{~mm}$, and their total length is $640 \mathrm{~m}$. The steam after the turbines is supplied to industrial needs, and steam using to heat the network water is supplied directly from boilers through reduction and cooling units (RCU). Aggregated technological scheme of CHP-5 is presented in Fig. 3 and contains next components: 42-48 - steam boiler units; 49-55 - steam pipelines from boiler units to steam collectors; 56, 57 - steam collectors; 58-66 - steam pipelines from collectors to RCU; 67-75 - RCU; 76-82 - network heaters; 83-89-network pumps. Turbines are not considered because in this scheme they do not impact on the heat energy output. The numbering of HS components (CHP-5) begins at position "42" as continuation of the numbering of components of $\mathrm{HN}$ for the formation of a jointed calculated scheme according to the comprehensive reliability analysis.

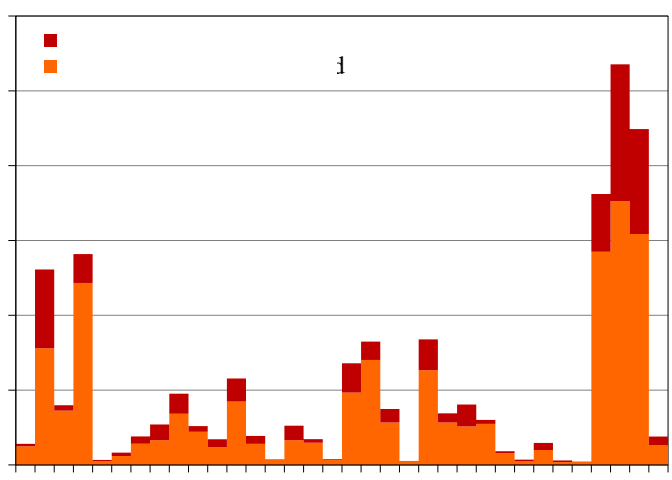

Fig. 2. Heat loads of united consumers of the DHS of Shelekhov city.

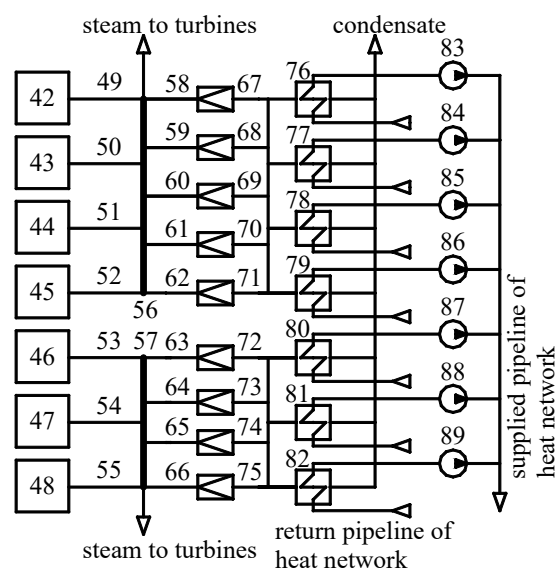

Fig. 3. Aggregated technological scheme of CHP5 of DHS in Shelekhov city. 


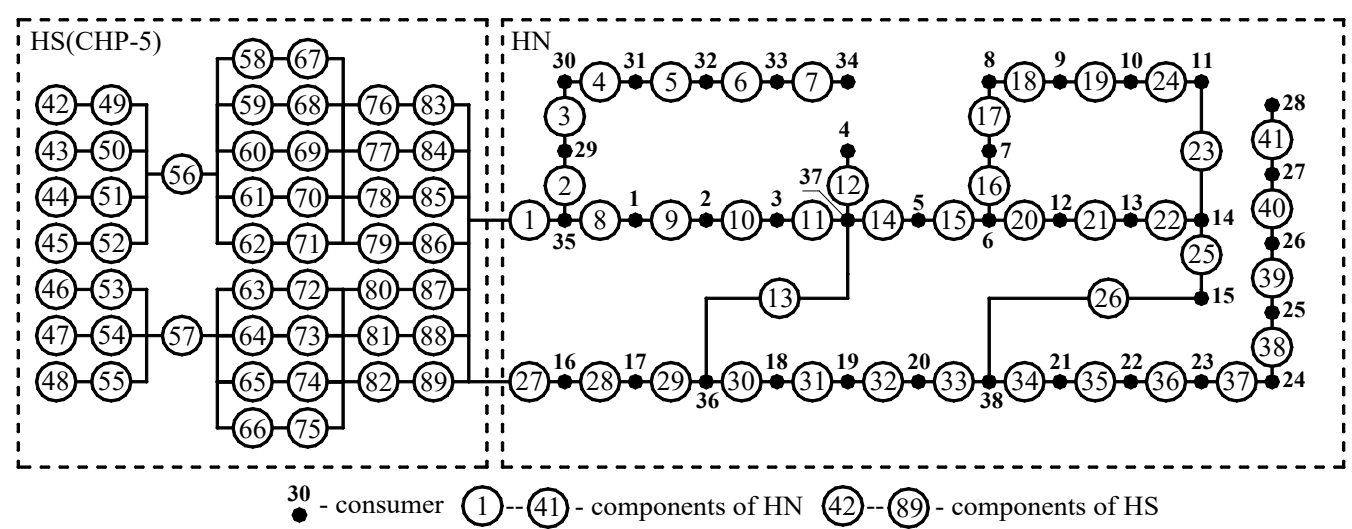

Fig. 4. Scheme of DHS in Shelekhov city for the reliability analysis.

TABle 1. TECHNiCAl AND RELIABILITy PARAMETERS OF COMPONENTS (SECTIONS) OF HEAT Network of THE AGgRegated CALCUlated Scheme of DHS IN SHELEKHOV CiTy

\begin{tabular}{|c|c|c|c|c|c|c|c|c|c|c|c|}
\hline \multirow{2}{*}{$\begin{array}{l}\text { No. of } \\
\text { section } \\
\text { (Fig. 1b) }\end{array}$} & \multirow{2}{*}{$\begin{array}{l}\text { Len- } \\
\text { gths, } \\
\text { m }\end{array}$} & \multirow{2}{*}{$\begin{array}{l}\text { Dia- } \\
\text { meter, } \\
\text { mm }\end{array}$} & \multirow{2}{*}{$\begin{array}{l}\text { Failure } \\
\text { rate, } \\
10^{-5}, \\
1 / h\end{array}$} & \multicolumn{2}{|c|}{$\begin{array}{l}\text { Restoration } \\
\text { rate, } 1 / \mathrm{h}\end{array}$} & \multirow{2}{*}{$\begin{array}{l}\text { No. of } \\
\text { section } \\
\text { (Fig. } \\
\text { 1b) }\end{array}$} & \multirow{2}{*}{$\begin{array}{l}\text { Len- } \\
\text { gths, } \\
\text { m }\end{array}$} & \multirow{2}{*}{$\begin{array}{l}\text { Dia- } \\
\text { meter, } \\
\text { mm }\end{array}$} & \multirow{2}{*}{$\begin{array}{l}\text { Failure } \\
\text { rate, } \\
10^{-5}, \\
1 / \mathbf{h}\end{array}$} & \multicolumn{2}{|c|}{$\begin{array}{l}\text { Restoration } \\
\text { rate, } 1 / \mathrm{h}\end{array}$} \\
\hline & & & & $\begin{array}{l}\text { without } \\
\text { ERS }\end{array}$ & $\begin{array}{l}\text { with } \\
\text { ERS }\end{array}$ & & & & & $\begin{array}{l}\text { without } \\
\text { ERS }\end{array}$ & $\begin{array}{l}\text { with } \\
\text { ERS }\end{array}$ \\
\hline 1 & 1297 & 720 & 2.59 & 0.047 & 0.071 & 22 & 60 & 377 & 0.12 & 0.067 & 0.116 \\
\hline 2 & 96 & 529 & 0.19 & 0.056 & 0.091 & 23 & 100 & 219 & 0.20 & 0.084 & 0.163 \\
\hline 3 & 928 & 529 & 1.86 & 0.056 & 0.091 & 24 & 154 & 219 & 0.31 & 0.084 & 0.163 \\
\hline 4 & 1715 & 529 & 3.43 & 0.056 & 0.091 & 25 & 161 & 325 & 0.32 & 0.072 & 0.128 \\
\hline 5 & 263 & 529 & 0.53 & 0.056 & 0.091 & 26 & 90 & 325 & 0.18 & 0.072 & 0.128 \\
\hline 6 & 670 & 402 & 1.34 & 0.065 & 0.111 & 27 & 2564 & 325 & 5.13 & 0.072 & 0.128 \\
\hline 7 & 658 & 273 & 1.32 & 0.077 & 0.143 & 28 & 523 & 325 & 1.05 & 0.072 & 0.128 \\
\hline 8 & 718 & 529 & 1.44 & 0.056 & 0.091 & 29 & 262 & 325 & 0.52 & 0.072 & 0.128 \\
\hline 9 & 338 & 529 & 0.68 & 0.056 & 0.091 & 30 & 93 & 325 & 0.19 & 0.072 & 0.128 \\
\hline 10 & 450 & 529 & 0.90 & 0.056 & 0.091 & 31 & 282 & 283 & 0.56 & 0.076 & 0.140 \\
\hline 11 & 346 & 529 & 0.69 & 0.056 & 0.091 & 32 & 342 & 317 & 0.68 & 0.072 & 0.130 \\
\hline 12 & 517 & 273 & 1.03 & 0.077 & 0.143 & 33 & 184 & 325 & 0.37 & 0.072 & 0.128 \\
\hline 13 & 115 & 273 & 0.23 & 0.077 & 0.143 & 34 & 49 & 325 & 0.10 & 0.072 & 0.128 \\
\hline 14 & 125 & 529 & 0.25 & 0.056 & 0.091 & 35 & 55 & 325 & 0.11 & 0.072 & 0.128 \\
\hline 15 & 142 & 529 & 0.28 & 0.056 & 0.091 & 36 & 204 & 325 & 0.41 & 0.072 & 0.128 \\
\hline 16 & 203 & 273 & 0.41 & 0.077 & 0.143 & 37 & 138 & 325 & 0.28 & 0.072 & 0.128 \\
\hline 17 & 174 & 273 & 0.35 & 0.077 & 0.143 & 38 & 134 & 256 & 0.27 & 0.079 & 0.149 \\
\hline 18 & 246 & 213 & 0.49 & 0.084 & 0.166 & 39 & 262 & 219 & 0.52 & 0.084 & 0.163 \\
\hline 19 & 70 & 213 & 0.14 & 0.084 & 0.165 & 40 & 138 & 159 & 0.28 & 0.092 & 0.192 \\
\hline 20 & 235 & 426 & 0.47 & 0.063 & 0.107 & 41 & 381 & 133 & 0.76 & 0.097 & 0.209 \\
\hline 21 & 204 & 394 & 0.41 & 0.065 & 0.113 & Total & 15700 & - & - & - & - \\
\hline
\end{tabular}


The reliability parameters of components of CHP-5 are presented in Table 2 and set in accordance with reliability properties of the equipment of the corresponding type and year of manufacture [26]. Addition, the failure rates of HS components are determined depending on the mean time between failures (MTBF), and also provided that each component is operated for a much longer than running-in time period, and its reliability decreases with an increase of operating time. Restoration rates are assumed the same for each type of equipment under the assumption that the emergency repairing time is independent of the service life.

Based on the DHS scheme (Fig. 1b) and the HS scheme (Fig. 3), a general integrated scheme of DHS for the probabilistic modelling of its functioning is formed, shown in Fig. 4. The numbering of the components corresponds to the initial schemes: $1-41-\mathrm{HN}$ components (sections), 42-89 - HS components; consumers and network nodes without load (for connecting pipe sections) are indicated by points 1 through 38 .

TABle 2. Reliability PARAMETERS OF COMPONENTS OF District HeAt SOURCE (CHP-5)

\begin{tabular}{|c|c|c|c|c|c|}
\hline $\begin{array}{l}\text { No. of } \\
\text { component } \\
\text { (Fig. 3) }\end{array}$ & Component type & $\begin{array}{l}\text { Time from the } \\
\text { beginning of operation, } \\
\text { thousand } h\end{array}$ & $\begin{array}{l}\text { Length of } \\
\text { steam } \\
\text { pipelines, } m\end{array}$ & $\begin{array}{l}\text { Failure rate, } \\
\mathbf{x 1 0}^{-5}, 1 / \mathrm{h}\end{array}$ & $\begin{array}{l}\text { Restoration } \\
\text { rate, } 1 / \mathrm{h}\end{array}$ \\
\hline 42 & Steam boiler No.1 & 203.1 & - & 1.55 & 0.0251 \\
\hline 43 & Steam boiler No. 2 & 211.1 & - & 1.61 & 0.0251 \\
\hline 44 & Steam boiler No.3 & 194.5 & - & 1.49 & 0.0251 \\
\hline 45 & Steam boiler No. 4 & 216 & - & 1.65 & 0.0251 \\
\hline 46 & Steam boiler No. 5 & 123.5 & - & 0.94 & 0.0251 \\
\hline 47 & Steam boiler No.6 & 103.5 & - & 0.79 & 0.0251 \\
\hline 48 & Steam boiler No.7 & 98.2 & - & 0.75 & 0.0251 \\
\hline 49 & $\begin{array}{l}\text { Steam pipeline from } \\
\text { boiler No.1 }\end{array}$ & 16.1 & 28 & 0.0095 & 0.1250 \\
\hline 50 & $\begin{array}{l}\text { Steam pipeline from } \\
\text { boiler No. } 2\end{array}$ & 25.1 & 28 & 0.0146 & 0.1250 \\
\hline 51 & $\begin{array}{l}\text { Steam pipeline from } \\
\text { boiler No.3 }\end{array}$ & 14.3 & 27 & 0.0082 & 0.1250 \\
\hline 52 & $\begin{array}{l}\text { Steam pipeline from } \\
\text { boiler No.4 }\end{array}$ & 38.9 & 23 & 0.0187 & 0.1250 \\
\hline 53 & $\begin{array}{l}\text { Steam pipeline from } \\
\text { boiler No.5 }\end{array}$ & 19.9 & 20 & 0.0082 & 0.1250 \\
\hline 54 & $\begin{array}{l}\text { Steam pipeline from } \\
\text { boiler No.6 }\end{array}$ & 22.9 & 25 & 0.0121 & 0.1250 \\
\hline 55 & $\begin{array}{l}\text { Steam pipeline from } \\
\text { boiler No.7 }\end{array}$ & 18.4 & 18 & 0.0071 & 0.1250 \\
\hline 56 & Steam collector 1 & 57.1 & 82 & 0.0987 & 0.1250 \\
\hline 57 & Steam collector 2 & 25.3 & 58 & 0.0310 & 0.1250 \\
\hline 58 & $\begin{array}{l}\text { Steam pipeline to } \\
\text { RCU-1 }\end{array}$ & 45.6 & 16 & 0.0153 & 0.1250 \\
\hline 59 & $\begin{array}{l}\text { Steam pipeline to } \\
\text { RCU-2 }\end{array}$ & 17.3 & 17 & 0.0063 & 0.1250 \\
\hline 60 & $\begin{array}{l}\text { Steam pipeline to } \\
\text { RCU-3 }\end{array}$ & 12.5 & 19 & 0.0050 & 0.1250 \\
\hline 61 & $\begin{array}{l}\text { Steam pipeline to } \\
\text { RCU-4 }\end{array}$ & 16.4 & 63 & 0.0217 & 0.1250 \\
\hline
\end{tabular}




\begin{tabular}{llllll}
\hline 62 & $\begin{array}{l}\text { Steam pipeline to } \\
\text { RCU-5 } \\
63\end{array}$ & 7.5 & 15 & 0.0024 & 0.1250 \\
& $\begin{array}{l}\text { Steam pipeline to } \\
\text { RCU-6 }\end{array}$ & 2.4 & 25 & 0.0012 & 0.1250 \\
64 & $\begin{array}{l}\text { Steam pipeline to } \\
\text { RCU-7 }\end{array}$ & 16.6 & 11 & 0.0038 & 0.1250 \\
65 & $\begin{array}{l}\text { Steam pipeline to } \\
\text { RCU-8 }\end{array}$ & 10 & 15 & 0.0031 & 0.1250 \\
66 & $\begin{array}{l}\text { Steam pipeline to } \\
\text { RCU-9 }\end{array}$ & 29.5 & 12 & 0.0076 & 0.1250 \\
$67-75$ & RCU (each) & - & - & 0.53 & 0.0510 \\
$76-82$ & Network heater & - & - & 0.05 & 0.0366 \\
$83-89$ & Network pump & - & - & 5.1 & 0.0115 \\
\hline
\end{tabular}

Information for assessing the reliability of the fuel supply to HS (CHP-5) or reliability of SFS is presented in Table 3. It's the designed values of the fuel needs (consumptions) and the distributions of random values of fuel needs and fuel supply. Fuel needs are determined by the heat load connected to HS and the necessary heat production in each calculation interval of the heating period.

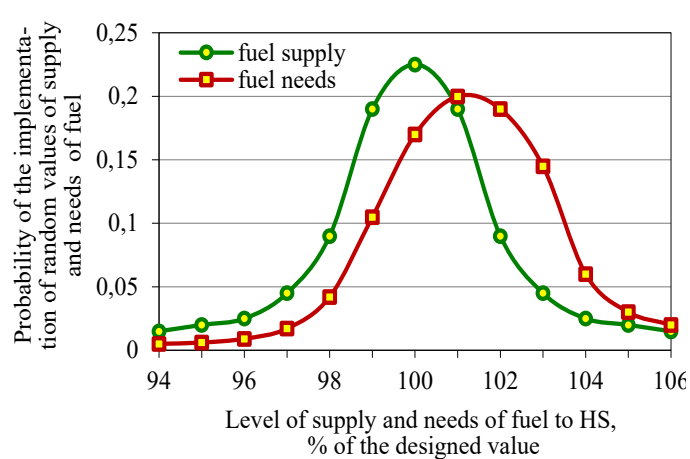

Fig. 5. Distributions of probabilities of random values of needs and supplies of fuel.

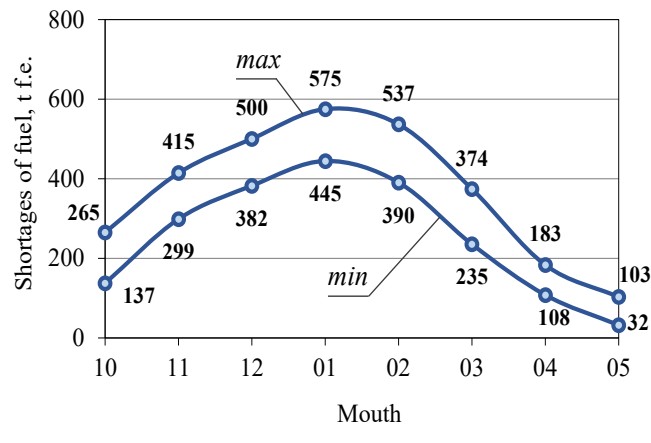

Fig. 6. Range of calculated possible shortages of fuel on HS.

TABle 3. Designed VAlues of The Fuel NeEds (CONSUMPtions), T F.E., AND Distributions of RANDOM VALUES OF FuEL NEEDS AND FuEL SuPPly

\begin{tabular}{|c|c|c|c|c|c|c|c|c|c|c|c|c|c|}
\hline \multirow{2}{*}{ Indicator } & \multicolumn{12}{|c|}{ Month } & \multirow{2}{*}{ Total } \\
\hline & 10 & & 11 & 12 & \multicolumn{2}{|c|}{01} & 02 & \multicolumn{2}{|c|}{$\mathbf{0 3}$} & 04 & 05 & & \\
\hline Fuel needs & 9504 & & 11558 & 14563 & & 042 & 11896 & \multicolumn{2}{|c|}{11681} & 8554 & 7481 & & 89279 \\
\hline Probability & \multicolumn{13}{|c|}{ Level of fuel needs and supply, \% of the designed values } \\
\hline of deviations & 94 & 95 & 96 & 97 & 98 & 99 & 100 & 101 & 102 & 103 & 104 & 105 & 106 \\
\hline fuel needs & 0.5 & 0.6 & 0.9 & 1.7 & 4.2 & 10 & 17 & 20 & 19 & 14 & 6,0 & 3.0 & 2.0 \\
\hline fuel supply & 1.5 & 2.0 & 2.5 & 4.5 & 9.0 & 19 & 22 & 19 & 9 & 4.5 & 2.5 & 2.0 & 1.5 \\
\hline
\end{tabular}

The calculated intervals correspond to the months indicated in the table in numerical format starting from the 10th (October), the total duration of the heating period is eight months - from October to May. During this period, the total fuel consumption for heating to consumers is about 
89 thousand $t$ of fuel equivalent (further $-t$ f.e.). Deviations of random values of fuel needs and supplies from the calculated level are determined based on statistical data of the actual indices of HS operation and are presented in the form of discrete distributions in Table 3 and in Fig. 5. The distribution of fuel supplies is even, and deviations in fuel needs are more probable in the range of values that exceed its calculated level.

Climatic parameters for reliability analysis (outdoor temperatures, duration of the heating period, etc.) are adopted for the conditions of Shelekhov in accordance with actual Sanitary regulations [42]. The coefficient of thermal accumulation is taken equal to $60 \mathrm{~h}$ for all consumers [6], [24]. Designed and reduced levels of heat supply to consumers correspond to the minimal permissible values of indoor air temperature equal to $20^{\circ} \mathrm{C}$ and $14{ }^{\circ} \mathrm{C}$, respectively [6].

\subsection{Reliability Analysis of SFS (Fuel Supply to HS)}

Calculation of fuel needs and fuel supplies was carried out according to a simulation algorithm using the statistical testing method described in [25], [38] and [40]. The generation of random values of the needs and supply of fuel in each calculation interval (month) is carried out in accordance with their distributions given in Table 3. As a modelling result, values of needs and supply of fuel are calculated for each month during the heating period. Based on these indices, the ranges of possible shortages of fuel are determined during the heating period, which are presented in Table 4 and in Fig. 6 . The total fuel shortage for the heating period is 2028-2953 $\mathrm{t}$ f. e. The equivalent amount of thermal energy undersupply is 14.9-21.6 thousand MWh.

TABle 4. Distribution of Possible Shortages of Fuel on HS, T F.E.

\begin{tabular}{|c|c|c|c|c|c|c|c|c|c|}
\hline \multirow{2}{*}{ Range of values } & \multicolumn{8}{|c|}{ Month } & \multirow{2}{*}{ Total } \\
\hline & 10 & 11 & 12 & 01 & 02 & 03 & 04 & 05 & \\
\hline \multicolumn{10}{|c|}{ Shortages of fuel, $t$ f.e. } \\
\hline upper bound & 265 & 415 & 500 & 575 & 537 & 374 & 183 & 103 & 2953 \\
\hline lower bound & 137 & 299 & 382 & 445 & 390 & 235 & 108 & 32 & 2028 \\
\hline \multicolumn{10}{|c|}{ Equivalent amount of thermal energy undersupply, thousand $\mathrm{MWh}$} \\
\hline upper bound & 1.67 & 2.61 & 3.15 & 3.62 & 3.38 & 2.36 & 1.15 & 0.65 & 18.6 \\
\hline lower bound & 0.87 & 1.88 & 2.41 & 2.80 & 2.46 & 1.48 & 0.68 & 0.20 & 12.8 \\
\hline
\end{tabular}

\subsection{Modelling of a Markov Random Process Describing the Operation of DHS, Considering the Results of the Reliability Analysis of SFS}

Modelling the evolution of states that describe the operating of DHS is based on the assumption of a simplest stream of events (Poisson stream) within its subsystems - HS and HN, while simultaneous failures of components from different subsystems are acceptable. In accordance with this, set of states are formed considering failures of HS and HN components, as well as their combinations (HS+HN). Along with the conditions corresponding to failures of DHS components, the states associated with the functioning of SFS are considered. The graph of states corresponding a considered structure of system events is shown in Fig. 7. The number of the graph component corresponds to the number of the failed component of the considered scheme of DHS presented in Fig. 4. 


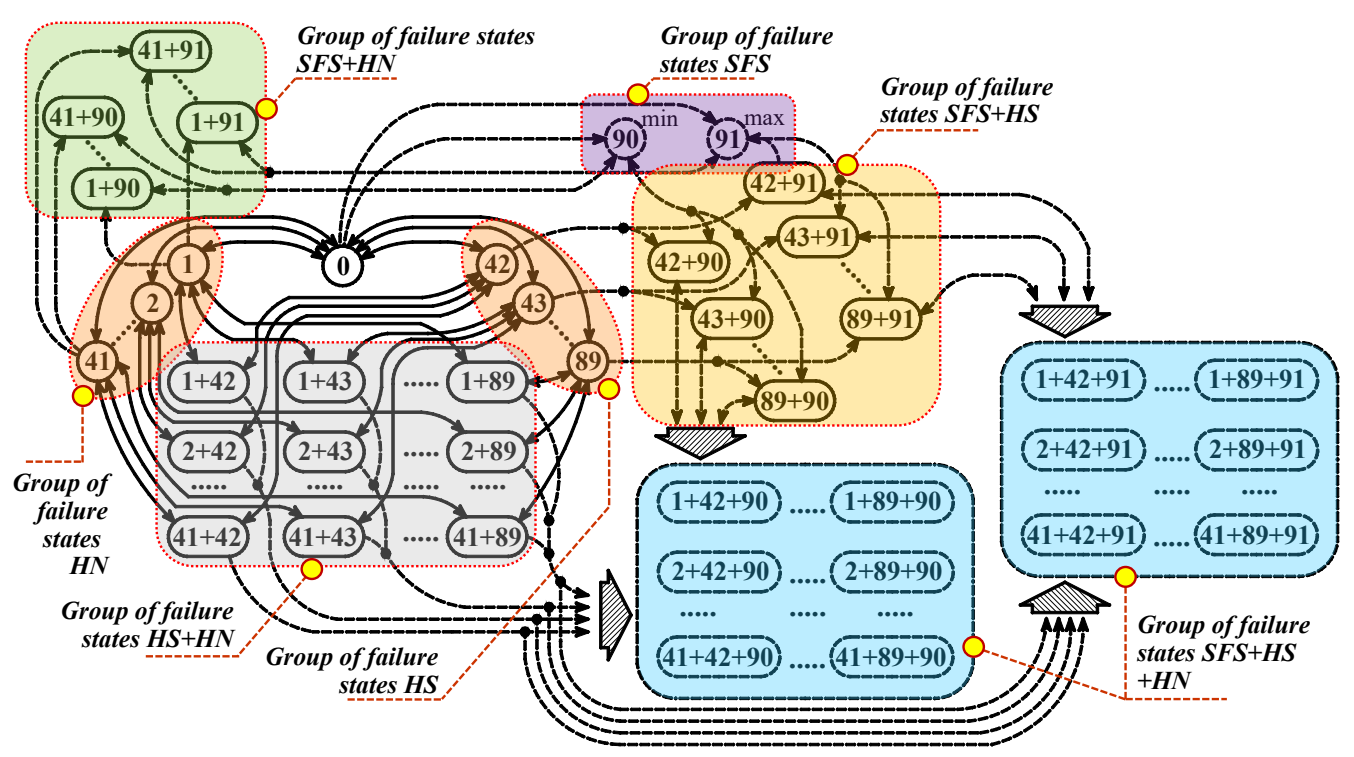

Fig. 7. Graph of the states of DHS in Shelekhov tacking into account the functioning of SFS (i.e. states corresponding to shortages of fuel supply to HS - 90 and 91).

States of simultaneous failure of two components of HS and HN are indicated by their numbers with the "+" sign. States on the graph are grouped according to combinations: to the left of the fully operational state " 0 " there is a subset of failure states of HN components (from 1 to 41 ), to the right is a subset of failure states of HS components (from 42 to 89), their combinations are given below - complex states of simultaneous failures of HN and HS components. The structure of events described by the presented graph takes into account the functioning of SFS. A group of states corresponding to the so-called imitating components (IC) with numbers 90 and 91 (Fig. 7), failures of which correspond to fuel shortages calculating by the statistical modelling of SFS, are integrated in the set of failures states of DHS components. Failure of each of these two IC leads to an interruption of heat energy output from HS in accordance with the minimum and maximum levels of fuel shortages (90-min and 91-max in Fig. 7) with intensity (rate) of transitions to these states which are set based on one failure for the heating period, which corresponds to the conditions for earlier assessing of fuel shortages in HS. So, the considered sates of failures of IC are compatible with failure states of any components of HS and HN. Subsets of these states are presented on the graph as aggregated groups corresponding to the joint failures of IC and components of HS, HN, as well as combinations of HS+HN.

The formed structure of events is modelled by a Markov random process considering IC failure conditions. This process is described by the corresponding system of linear stationary Kolmogorov equations. The result of its solution are the probabilities of states corresponding to failures of DHS components and components imitating of fuel shortages. Further, these calculation results (more than 3000 variables) are used to determine the nodal RI.

\subsection{Modelling of Emergency Modes of DHS}

Determination of the levels of heat supply to consumers in different states of DHS, including interruptions of the fuel supply to HS, it is carried out on the basis of multivariate calculations of the flow distribution in the network using models of the THC, a detailed description of which is given in [27]. The results of the calculation of post-emergency network modes contain a 
significant amount of data. The ratio of the levels of heat supply to consumers in states corresponding to failures of HS and HN components is presented in Fig. 8.

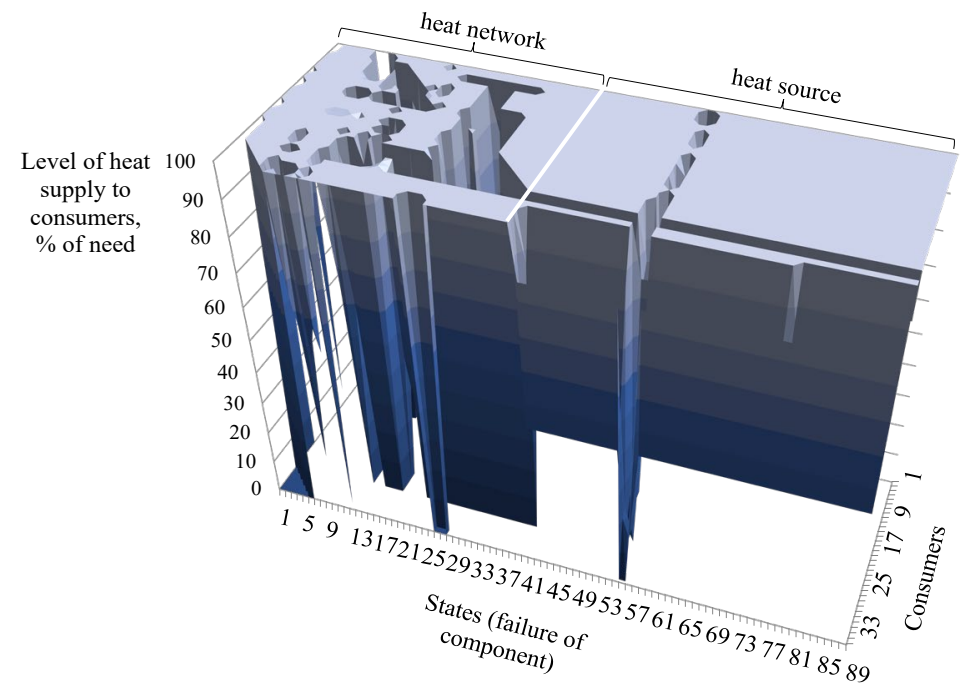

Fig. 8. Levels of heat supply to consumers in case of failures of components of DHS subsystems (HS and HN).

On the vertical axis of this diagram, the relative level of heat supply to consumers is set in percent $(\%)$ of the need (required) value. On the horizontal axes, numbers of DHS states (corresponding to failures of HS and HN components) and numbers of consumers are set. The plane of $100 \%$ heat supply has "dips" in the field of interruptions of the required heating. It can be seen from the figure that a large proportion of interruptions are related to failures of $\mathrm{HN}$ components, while failures of HS components almost in any cases lead to interruptions in the heat supply to consumers farthest from it (consumers 28, 34 in Fig. 1b).

\subsection{Determining of Nodal RI}

Assessment of the reliability of heat supply to consumers of the considered DHS is based on the determination of two nodal RI: availability factor $(K)$ and failure-free operation probability $(R)$. These indices are calculated by dependencies developed in the framework of the methodology of a comprehensive reliability analysis of DHS [25], [38]-[40]. The results of calculations of nodal RI are given in Table 5 and Fig. 9.

According to the applying reliability analysis technique, $K$ is determined for the designed (calculated) level of heat supply (at an indoor air temperature of $20^{\circ} \mathrm{C}$ ), and $R$ - for a reduced level (at an indoor air temperature of $14{ }^{\circ} \mathrm{C}$ ). Additional indices were also calculated: the average summary time for the heating period of the interruption of the designed heat supply (that is, the temperature of the indoor air decreased below the calculated value) of consumer $(Z)$, and the failure frequency of the reduced level of heat supply to consumer $(N)$. All indices are determined considering the time redundancy of consumers related to the heat accumulating effect. 
TABLE 5. NODAL RI OF DHS IN SHELEKHOV CITY

\begin{tabular}{ccccc|cccccc}
\hline $\begin{array}{c}\text { Consumer } \\
\text { (Fig. 4) }\end{array}$ & $\mathbf{K}$ & $\mathbf{R}$ & $\mathbf{Z , ~ h}$ & $\begin{array}{c}\mathbf{N}, \\
\mathbf{1 / y e a r}\end{array}$ & $\begin{array}{c}\text { Consumer } \\
\text { (Fig. 4) }\end{array}$ & $\mathbf{K}$ & $\mathbf{R}$ & $\mathbf{Z , ~ h ~}$ & $\begin{array}{c}\mathbf{N}, \\
\mathbf{1 / y e a r}\end{array}$ \\
\hline 1 & 0.948 & 0.962 & 300 & 0.04 & 18 & 0.937 & 0.935 & 366 & 0.07 \\
2 & 0.943 & 0.940 & 328 & 0.06 & 19 & 0.934 & 0.933 & 383 & 0.07 \\
3 & 0.939 & 0.935 & 351 & 0.07 & 20 & 0.934 & 0.924 & 383 & 0.08 \\
4 & 0.935 & 0.931 & 374 & 0.07 & 21 & 0.926 & 0.908 & 428 & 0.10 \\
5 & 0.935 & 0.937 & 377 & 0.07 & 22 & 0.923 & 0.906 & 445 & 0.10 \\
6 & 0.934 & 0.935 & 383 & 0.07 & 23 & 0.921 & 0.900 & 457 & 0.11 \\
7 & 0.933 & 0.933 & 388 & 0.07 & 24 & 0.914 & 0.893 & 496 & 0.11 \\
8 & 0.932 & 0.937 & 394 & 0.07 & 25 & 0.907 & 0.886 & 535 & 0.12 \\
9 & 0.932 & 0.937 & 394 & 0.07 & 26 & 0.900 & 0.879 & 574 & 0.13 \\
10 & 0.931 & 0.941 & 400 & 0.06 & 27 & 0.894 & 0.872 & 613 & 0.14 \\
11 & 0.931 & 0.941 & 400 & 0.06 & 28 & 0.887 & 0.866 & 653 & 0.14 \\
12 & 0.938 & 0.933 & 360 & 0.07 & 29 & 0.913 & 0.910 & 501 & 0.09 \\
13 & 0.938 & 0.932 & 360 & 0.07 & 30 & 0.906 & 0.900 & 541 & 0.11 \\
14 & 0.941 & 0.935 & 337 & 0.07 & 31 & 0.899 & 0.891 & 583 & 0.12 \\
15 & 0.942 & 0.929 & 331 & 0.07 & 32 & 0.892 & 0.882 & 625 & 0.13 \\
16 & 0.949 & 0.946 & 291 & 0.06 & 33 & 0.884 & 0.873 & 667 & 0.14 \\
17 & 0.947 & 0.944 & 303 & 0.06 & 34 & 0.877 & 0.864 & 708 & 0.15 \\
\hline
\end{tabular}

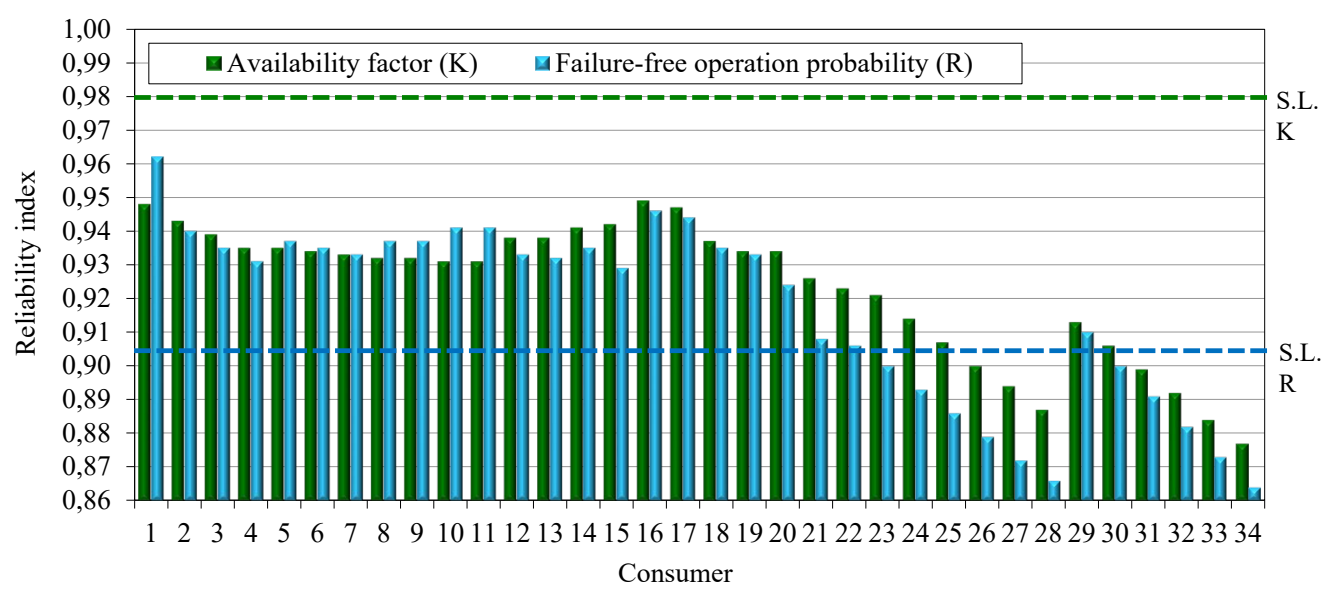

Fig. 9. Nodal RI of DHS in Shelekhov (number of consumers correspond to Fig. 3 and Fig. 6; S.L. - standard level).

As can be seen from the Table 5 and Fig. 9, the RI values differ significantly among consumers. Consumers located far from the HS, and connected to the non-reserved (noncircuit) part of the network, have the lowest level of reliability of both the designed and reduced heat supply. Index $K$ takes values in range from 0.877 (consumer 34) to 0.949 (consumer 16); and index $R$ takes values in range from 0.864 (consumer 34) to 0.962 (consumer 1). Index $Z$ for the most "unreliable" consumer 34 is 708 hours, and the number of heat supply failures $N$ is 0.151 /year or one time in 6.8 years. 
In the requirements for reliability of heat supply to consumers, given in [6] the following standard values of nodal RI for DHS are determined: $K$ no less than 0.979 (or $Z$ no more than $120 \mathrm{~h}$ ); $R$ not less than 0.905 (or $N$ not more than $0.11 /$ year). According to the results of the reliability analysis of considered DHS (Table 5 and Fig. 11), the requirement for $K$ are not met for all consumers of the system, the requirement for $R$ are not met for $32 \%$ of consumers (in Table 5, the corresponding cells are greyed out). This RI reflect the comprehensive effect of all DHS subsystems, taking into account the fuel supply to HS (SFS functioning), on the reliability of heat supply for each consumer.

\section{DECOMPOSITION RELIABILITY ANALYSIS OF DHS IN SHELEKHOV CiTY AND DISCUSSION}

Based on the result obtained, the decomposition reliability analysis is carried out, which allows to determine the influence of each considered subsystem on the reliability of heat supply to consumers. The decomposition assessment of reliability of heat supply to consumers in Shelekhov is carried out in 4 stages in depend on which system it related to: 1) SFS; 2) DHS; 3) HS; 4) HN. Modelling the functioning modes of DHS subsystems, determining of probabilities of their implementation, and calculating RI are carried out according to the decomposition analysis approaches described in the framework of the comprehensive reliability analysis technique presented in [25], [38]-[40].

TABLE 6. GENERALIZED RESUlts OF COMPREHENSIVE AND DECOMPOSITION RELIABILITY ANALYSIS OF DHS IN SHELEKHOV CITY

\begin{tabular}{|c|c|c|c|c|c|c|c|c|c|c|c|c|}
\hline \multirow[t]{3}{*}{ System } & \multicolumn{8}{|c|}{ Ranges of values of nodal RI } & \multicolumn{2}{|c|}{$\begin{array}{l}\text { Increase in RI } \\
\text { for subsystems } \\
\text { relative to the } \\
\text { initial value, \% }\end{array}$} & \multicolumn{2}{|c|}{$\begin{array}{c}\text { Part of } \\
\text { consumers with } \\
\text { a standard level } \\
\text { of RI, } \%\end{array}$} \\
\hline & \multicolumn{2}{|c|}{$K$} & \multicolumn{2}{|c|}{$\boldsymbol{R}$} & \multicolumn{2}{|c|}{$Z, \mathbf{h}$} & \multicolumn{2}{|c|}{$N, 1 /$ year } & \multirow[t]{2}{*}{$\boldsymbol{K}$} & \multirow[t]{2}{*}{$\boldsymbol{R}$} & \multirow[t]{2}{*}{$\boldsymbol{K}$} & \multirow[t]{2}{*}{$R$} \\
\hline & $\min$ & $\max$ & $\min$ & $\max$ & $\max$ & $\min$ & $\max$ & $\min$ & & & & \\
\hline DHS+SFS & 0.877 & 0.949 & 0.864 & 0.962 & 708 & 291 & 0.15 & 0.04 & - & - & 0 & 68 \\
\hline SFS & 0.896 & 0.969 & 0.889 & 0.985 & 602 & 179 & 0.12 & 0.02 & 2.1 & 2.6 & 0 & 88 \\
\hline DHS & 0.902 & 0.976 & 0.873 & 0.967 & 564 & 138 & 0.14 & 0.03 & 2.8 & 0.7 & 0 & 74 \\
\hline HS & 0.926 & 0.994 & 0.904 & 0.987 & 428 & 36 & 0.1 & 0.01 & 5.1 & 4.6 & 9 & 56 \\
\hline $\mathrm{HN}$ & 0.911 & 0.987 & 0.883 & 0.983 & 513 & 75 & 0.12 & 0.02 & 3.9 & 2.2 & 0 & 53 \\
\hline
\end{tabular}

The results of the decomposition and comprehensive reliability analysis of DHS of Shelekhov are present in the jointed form in Table 6. Figure 10a and 10b shows the ranges of values of $K$ and $R$ for DHS taking into account SFS functioning and with the separation of RI for subsystems. The relationships of nodal RI for subsystems with respect to the level of comprehensive assessment are shown in Fig. 10c. 

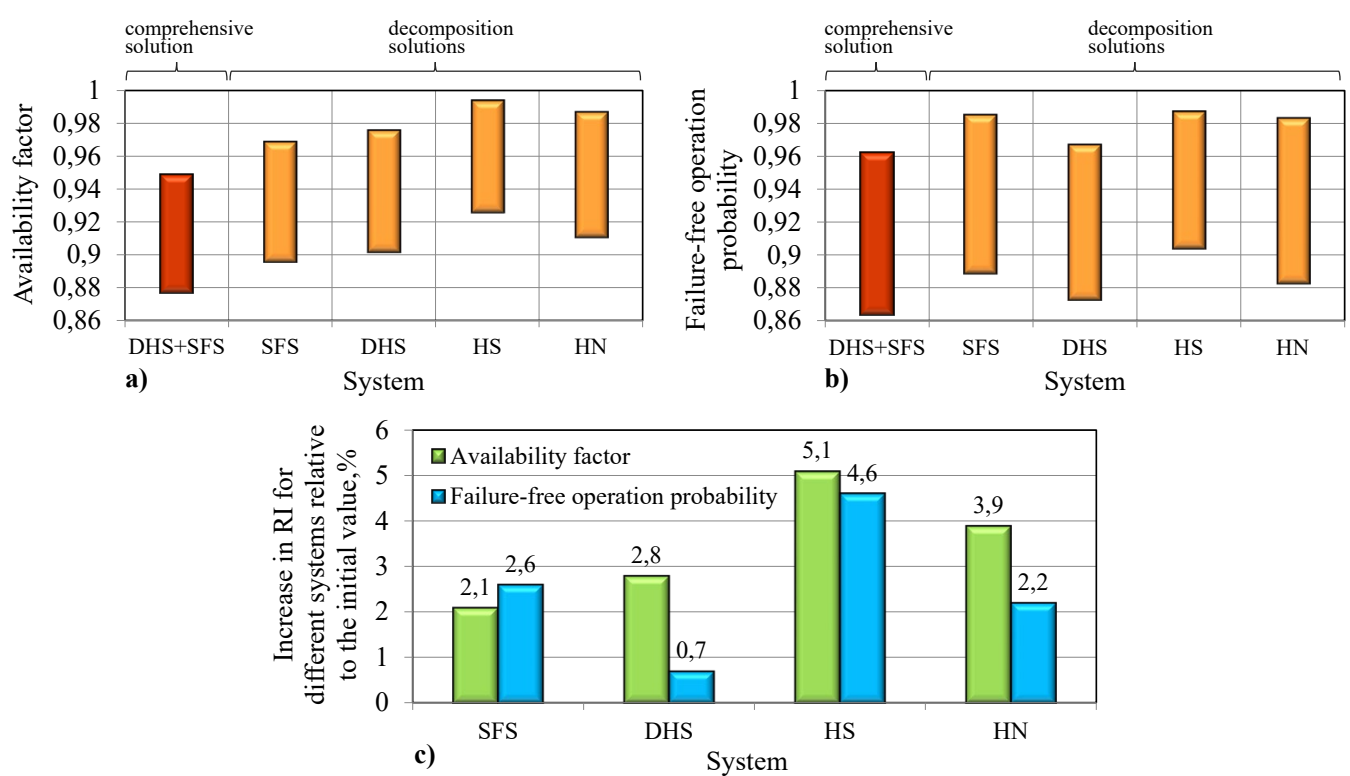

Fig. 10. Summarizing result of a comprehensive and decomposition analysis of the reliability of DHS (heat supply to consumers) in Shelekhov: a) range of $K$ values; b) range of $R$ values; c) average values of the increase in nodal RI for subsystems in relation to the level of indices of the jointed system DHS+SFS.

Analysis of the presented results allows us to formulate the following conclusions about preliminary general directions for improving the reliability of heat supply to consumers of DHS in Shelekhov.

1. Fuel supply interruptions on HS in the considered system reduce the reliability of designed level of heat supply to consumers to a greater extent than failures of HS and HN components. This is confirmed by lower values of $K$ for SFS compared with DHS (Fig. $10 \mathrm{a}, \mathrm{c})$. The range of increase in its values to the standard level is from 1 to $9.3 \%$. Improving the reliability of SFS is achieved by regulating and increasing fuel reserves, providing the system with additional sources of fuel and a more reliable system for its transportation.

2 . Index $K$, calculated relative to HS, has the highest values, and for some consumers it complies with the standard. For the group of jointed consumers with the highest values of this index (consumers 1-20), achieving its standard level will require a minimal redundancy in the HS scheme. For other consumers, HS-related $K$ is low. To increase it, more significant measures for increasing of functional and structural HS redundancy will be required. It is also necessary to consider that the installed heat capacity of CHP-5 is significantly higher than the required generation for heat supply to house-hold consumers of the city, since most of this power covers technological loads. Therefore, there is an additional reserve for heating during periods of low heat loads.

3. The reliability of the reduced level of heat supply to consumers, characterized by index $R$, is affected to a greater extent by the failures of the DHS components (Fig. 10b,c). Decomposition of RI is showed that $\mathrm{HN}$ is a less reliable subsystem (Fig. 10a,b), which corresponds to lower RI values in comparison with HS. In this regard, one of the main directions of increasing the reliability of DHS are related to the implementation of a set of measures for the component and structural redundancy of HN. Such, the additional looped network connections (bypass) in the network and duplication of some sections will provide the required level of reduced heating to consumers in emergency modes. At the same time, 
the obtained $\mathrm{R}$ values for some consumers correspond to the standard ones, while additional structural redundancy of the network will lead to a decrease in the reliability of the design level of heating to consumers due to an increase of number of possible failures (redundancy conflict of the 2nd type [6], [25]). Replacing the network components with more reliable ones and increasing its restoration rates (incl. due to improvement of ERS) will increase the values of both indices $(K$ and $R$ ).

4. The presented results of the reliability analysis are aimed at obtaining the basis for making further decisions on searching the optimal ratio of measures to increase the reliability of heat supply to consumers. The rational distribution of reliability both in DHS (i.e. for subsystems - HS and HN) and SFS, and in the ways to ensure it (functional, component, structural redundancy, fuel reserves, energy storages, etc.) are a subject of special research of the problems of reliability synthesis. For example, the methodology for the optimal increase/ensuring the reliability parameters of DHS components as the one of the problems of reliability synthesis is considered in articles [43] and [44]. Some reliability optimization issues for the DHS with prosumers are presented in works [45]-[47].

5. Based on provided studies and calculations for actual DHS, functioning in Shelekhov, the practical applicability of methods and models of a comprehensive analysis of the reliability of heat supply to consumers is confirms and its successful application for solving practical problems are demonstrated.

\section{Conclusions}

The problem of reliability of the functioning of DHS, or reliability of heat supply to consumers connected to DHS, is becoming more and more relevant due to the increase in heat loads (number of connected consumers), increase wear of equipment, as well as the development of these systems (in particular, the transition to 4GDH system), which leads to complication both their technological structure (different energy sources, incl. renewable ones, prosumers, etc.) and management approaches. The reliable and safe functioning of DHS is one of the priority conditions for the stability and development of the economy for countries with a high part of district heating (Russia and other countries of Eastern Europe, some countries of Northern Europe, China).

The existing methods for analysing the reliability of DHS subsystems (HS and HN), as well as the reliability of SFS (reliability of the fuel supply to HS) were considered. Based on analysis of this methods, directions of developing research in this area are proposed. As the main area of research, the problem of a comprehensive reliability analysis of heat supply to consumers and the development of methods for its solution is substantiated. In the previous works of the author (also with co-authors), a detailed description of the methods, models and algorithms for solve the problems of a comprehensive reliability analysis of DHS (reliability of heat supply to consumers) is presented. Corresponding references are provided.

The main idea of a comprehensive approach to the reliability analysis of DHS is a joint study and modelling of different technological processes and corresponding subsystems that impact the reliability of heat supply to consumers. This approach allows to get the most valid assessments of RI taking into account the total impact on heating reliability of the whole process chain, including fuel supply, production, distribution and consumption of thermal energy. On the other hand, a decomposition reliability assessment carried out on the basis of a comprehensive reliability analysis allows us to identify the most "bottlenecks" in the system, ensuring the basis for the most effective strategy to increase its reliability. The other effects and advantages of a comprehensive reliability analysis of DHS are described in [38][40]. 
The main focus of the article is on the results of practical studies (case studies) conducted for the existing and actual DHS in Shelekhov city (Irkutsk region, Siberia) based on the previously developed methodology for a comprehensive reliability analysis of DHS. The main stages of the reliability analysis are considered, including the preparation of initial data, modelling of the fuel supply to HS based on the statistical testing method (Monte Carlo method), probabilistic modelling of the joint operation of HS and HN based on the Markov random process, modelling of emergency modes in the DHS based on the methods of THC, calculation of nodal RIs.

According to the data obtained and considering the current standard requirements for RI, the most unreliable consumer nodes of the studied system were identified. A decomposition reliability analysis of DHS was carried out, as a result of which the levels of impact of each of the studied subsystems (SFS, HS and HN) on the reliability of heat supply to consumers were determined. Based on the results of a comprehensive and decomposition analysis of reliability, preliminary general directions for increasing the reliability of heat supply to consumers have been formulated.

The presented results of practical research are aimed at providing the basis for making further solutions on the optimal ratio of measures to ensuring or improving the reliability of DHS. The rational distribution of reliability both on various subsystems and redundancy methods is a complex of problems of the synthesis (optimization) of reliability, which are the subject of separate study in the framework of directions of this work. For example, some of this studies are presented in [43]-[47]. The practical studies presented in the article confirm the effectiveness and applied significance of the previously developed methods and models of the comprehensive reliability analysis of DHS. The directions of further research are related to the improving of this methodology and the development on its basis of a scientific and methodological basis for a comprehensive (considering all technological processes) synthesis of the reliability of heat supply to consumers.

\section{ACKNOWLEDGEMENTS}

The research was performed at Melentiev Energy Systems Institute SB RAS under the support of Russian Foundation for Basic Research (Grant №20-08-00488A).

\section{REFERENCES}

[1] Lund H., et al. The status of 4th generation district heating: Research and results. Energy 2018:164:147-159. https://doi.org/10.1016/i.energy.2018.08.206

[2] Vigants E., Prodanuks T., Vigants G., Veidenberg I., Blumberga D. Modelling of Technological Solutions 4th Generation DH Systems. Environmental and Climate Technologies 2017:20:5-23. https://doi.org/10.1515/rtuect2017-0007

[3] Volkova A., Masatin V., Siirde A. Methodology for evaluating the transition process dynamics towards 4th generation district heating networks. Energy 2018:150:253-261. https://doi.org/10.1016/j.energy.2018.02.123

[4] Ziemele J., Gravelsins A., Blumberga A., Blumberga D. The effect of energy efficiency improvements on the development of 4th generation district heating. Energy Procedia 2016:95:522-527. https://doi.org/10.1016/j.egypro.2016.09.079

[5] Ziemele J., Gravelsins A., Blumberga A., Blumberga D. Combining energy efficiency at source and at consumer to reach 4th generation district heating: Economic and system dynamics analysis. Energy 2017:137:595-606. https://doi.org/10.1016/j.energy.2017.04.123

[6] Sennova E. V., et al. Reliability of heat supply systems. Novosibirsk: Nauka, 2000.

[7] Lisnianski A., Elmakias D., Hanoch B. H. A multi-state Markov model for a short-term reliability analysis of a power generating unit. Reliability engineering \& system safety 2012:98:1-6. https://doi.org/10.1016/j.ress.2011.10.008 
[8] Shahhosseini A., Olamaei J. An efficient stochastic programming for optimal allocation of combined heat and power systems for commercial buildings using. Thermal Science and Engineering Progress 2019:11:133-141. https://doi.org/10.1016/j.tsep.2019.03.016

[9] Haghifam M., Manbachi M. Reliability and availability modelling of combined heat and power (CHP) systems. International journal of electrical power \& energy systems 2011:33(3):385-393. https://doi.org/10.1016/j.ijepes.2010.08.035

[10] Sabouhi H., Abbaspour A., Fotuhi-Firuzabad M., Dehghanian P. Reliability modeling and availability analysis of combined cycle power plants. International Journal of Electrical Power \& Energy Systems 2016:79:108-119. https://doi.org/10.1016/j.ijepes.2016.01.007

[11] Kumar P., Kumar Singh L., Kumar C. Performance evaluation of safety-critical systems of nuclear power plant systems. Nuclear Engineering and Technology 2020:52(3):560-67. https://doi.org/10.1016/j.net.2019.08.018

[12] Jiang J., Zhang L., Wang Y., Peng Y., Zhang K., He W. Markov reliability model research of monitoring process in digital main control room of nuclear power plant. Safety Science 2011:49(6):843-851. https://doi.org/10.1016/j.ssci.2011.01.014

[13] Wang J.-J., Fu C., Yang K., Zhang X.-T., Shi G., Zhai J. Reliability and availability analysis of redundant BCHP (building cooling, heating and power) system. Energy 2013:61:531-40. https://doi.org/10.1016/j.energy.2013.09.018

[14] El-Nashar A. Optimal design of a cogeneration plant for power and desalination taking equipment reliability into consideration. Desalination 2008:229(1-3):21-32. https://doi.org/10.1016/j.desal.2007.07.024

[15] Woo S., Nam Z. Semi-Markov reliability analysis of three test/repair policies for standby safety systems in a nuclear power plant. Reliability engineering \& system safety 1991:31:1-30. https://doi.org/10.1016/0951-8320(91)90033-4

[16] Korolyuk V. S., Turbin A. F. Semi-Markov processes and their applications. Kiev: Naukova Dumka, 1976.

[17] Jiang J., Gao W., Wei X., Li Y., Kuroki S. Reliability and cost analysis of the redundant design of a combined cooling, heating and power (CCHP) system. Energy Conversion and Management 2019:199:111988. https://doi.org/10.1016/j.enconman.2019.111988

[18] Wang J., You S., Zong Y., Chresten T., Dong Z. Y., Zhou Y. Flexibility of combined heat and power plants: A review of technologies and operation strategies. Applied Energy 2019:252:113445. https://doi.org/10.1016/j.apenergy.2019.113445

[19] Frangopoulos C. A., Dimopoulos G. G. Effect of reliability considerations on the optimal synthesis, design and operation of a cogeneration system. Energy 2004:29(3):309-329. https://doi.org/10.1016/S0360-5442(02)00031-2

[20] Buslenko N. P. Modeling of complex systems. Moscow: Nauka, 1978.

[21] Shu L, Chen L., Jin J., Yu J., Sun F., Wu C. Functional reliability simulation for a power-station's steam-turbine. Applied Energy 2005:80(1):61-66. https://doi.org/10.1016/j.apenergy.2004.02.004

[22] Ahn H., Rim D., Pavlak G. S., Freihaut J. D. Uncertainty analysis of energy and economic performances of hybrid solar photovoltaic and combined cooling, heating, and power (CCHP+PV) systems using a Monte-Carlo method. Applied Energy 2019:255:113753. https://doi.org/10.1016/j.apenergy.2019.113753

[23] Khasilev V. Y., Takaishvili M. K. About fundamentals of the technique for calculation and redundancy of heat networks. Teploenergetika 1972:4:14-19.

[24] Sennova E. V., Sidler V. G. Mathematical modeling and optimization of developing heat supply systems. Novosibirsk: Nauka, 1985.

[25] Stennikov V. A., Postnikov I. V. Methodological support for a comprehensive analysis of fuel and heat supply reliability. In: Sustaining power resources through energy optimization and engineering, ed. by Vasant P., Voropai N. I. Hershey PA: Engineering science reference (an imprint of IGI Global), 2016. https://doi.org/10.4018/978-14666-9755-3

[26] Diakov A. F., et al. Reliability of energy systems: problems, models and methods for solving them. Novosibirsk: Nauka, 2014.

[27] Merenkov A. P., Khasilev V. Ya. Theory of hydraulic circuits. Moscow: Nauka, 1985.

[28] Ionin A. A. Reliability of heat network systems. Moscow: Strojizdat, 1989.

[29] Valincius M., Zutautaite I., Dundulis G., Rimkevicius S., Janulionis R., Bakas R. Integrated assessment of failure probability of the district heating network. Reliability Engineering and System Safety 2015:133:314-322. https://doi.org/10.1016/j.ress.2014.09.022

[30] Zorkaltsev V. I., Kolobov Y. I. A simulation model to study reliability of fuel supply to heat generating units. Bulletin of Komi branch of the USSR Academy of Sciences 1984:33-39.

[31] Nekrasov A. S., Velikanov M. A., Gorunov P. V. Reliability of fuel supply to power plants: methods and models of studies. Moscow: Nauka, 1990,

[32] Zorkaltsev V., Ivanova E. Intensity and synchronism of fluctuations in fuel demand for heating by economic region of the country. Bulletin of the USSR Academy of Sciences: Energy and transport 1990:6:14-22.

[33] Sukharev M. G., et al. Reliability of gas and oil supply systems. Moscow: Nedra, 1994.

[34] Rimkevicius S., Kaliatka A., Valincius M., Dundulis G., Janulionis R., Grybenas A., Zutautaite I. Development of approach for reliability assessment of pipeline network systems. Applied Energy 2012:94:22-33. https://doi.org/10.1016/j.apenergy.2012.01.015 
[35] Amirat A., Mohamed-Chateauneuf A., Chaoui K. Reliability assessment of underground pipelines under the combined effect of active corrosion and residual stress. International Journal of Pressure Vessels and Piping 2006:83(2):107-117. https://doi.org/10.1016/j.ijpvp.2005.11.004

[36] Adefarati T., Bansal R. C. Reliability assessment of distribution system with the integration of renewable distributed generation. Applied Energy 2017:185:158-171. https://doi.org/10.1016/j.apenergy.2016.10.087

[37] Ramirez-Marquez J. E., Coit D. W. Multi-state component criticality analysis for reliability improvement in multistate systems. Reliability Engineering and System Safety 2007:92:1608-1619. https://doi.org/10.1016/j.ress.2006.09.014

[38] Stennikov V. A., Postnikov I. V. Methods for the integrated reliability analysis of heat supply. Power Technology and Engineering 2014:47(6):446-453. https://doi.org/10.1007/s10749-014-0467-0

[39] Stennikov V. A., Postnikov I. V. Methods for comprehensive analysis of heat supply reliability. International journal of energy optimization and engineering 2013:2(4):120-142. https://doi.org/10.4018/ijeoe.2013100107

[40] Stennikov V. A., Postnikov I. V. Comprehensive analysis of the heat supply reliability. Bulletin of Russian Academy of Sciences: Energy 2011:2:107-121.

[41] Bukher F. S., et al. Study of operating modes and a feasibility study for the reconstruction of heating networks in the Shelekhov city taking into account the forecasting loads. Report on research work. Irkutsk: ESI SB RAS, 2008.

[42] Sanitary regulations SNiP 23-01-99 "Construction climatology". Moscow: State Committee of the Russian Federation for construction and housing and communal services, 2000.

[43] Postnikov I., Stennikov V., Mednikova E., Penkovskii A. A methodology for optimization of component reliability of heat supply systems. Energy Procedia 2017:105:3083-3088. https://doi.org/10.1016/j.egypro.2017.03.643

[44] Postnikov I., Stennikov V., Mednikova E., Penkovskii A. Methodology for optimization of component reliability of heat supply systems. Applied Energy 2018:227:365-374. https://doi.org/10.1016/j.apenergy.2017.11.073

[45] Postnikov I., Stennikov V., Penkovskii A. Prosumer in the district heating systems: Operating and reliability modeling. Energy Procedia 2019:158:2530-2535. https://doi.org/10.1016/j.egypro.2019.01.411

[46] Postnikov I. Methods for optimization of time redundancy of prosumer in district heating systems. Energy Reports 2020:6(2):214-220. https://doi.org/10.1016/j.egyr.2019.11.065

[47] Postnikov I. Providing the Reliability of Heating of Prosumers taking into account the Functioning of Their Own Heat Sources in District Heating Systems. IEEE Xplore Digital Library 2019 (International Multi-Conference on Industrial Engineering and Modern Technologies - FarEastCon):1-7. https://doi.org/10.1109/FarEastCon.2019.8934913 